Асист. Л.О. Пархоменко, В.С. Дюкарев

Assistant L.A. Parkhomenko, V.S. Dyukarev

\title{
РОЗРОБКА МАТЕМАТИЧНОЇ МОДЕЛІ ВИЗНАЧЕННЯ РАЦІОНАЛЬНИХ ВАРІАНТІВ УВ'ЯЗКИ ОБЕРТУ СОСТАВІВ ПРИПИСКИ РІЗНИХ ЗАЛІЗНИЦЬ В ЗАГАЛЬНИЙ ОБІГ
}

\section{DEVELOPMENT OF A MATHEMATICAL MODEL FOR DETERMINING THE RATIONAL OPTION OF LINKING MOMENTUM-PROOF OF REGISTRY DIFFERENT RAILWAY IN TOTAL TURNOVER}

\author{
Представив д-р техн. наук, професор Д.В. Ломотько
}

Вступ і актуальність теми. В умовах росту конкуренції на транспортному ринку виникають нові вимоги щодо технологій управління залізничним пасажирським комплексом з позиції системного підходу [1]. Одним із напрямків формування нових технологій організації перевезень $\epsilon$ реалізація кільцювання схем обігу пасажирських составів на залізничній мережі на основі застосування сучасних досягнень у галузі інтелектуальних систем. Такий підхід дозволить дослідити усі можливі варіанти системи організації пасажирських поїздопотоків на полігоні мережі, що, як наслідок, буде сприяти комплексному вирішенню задачі розрахунку плану формування та розробки раціональних схем обігу пасажирських поїздів на мережі залізниць.

Існуючі підходи до вирішення задач розробки схем обігу пасажирських складів на практиці зводяться до використання експертних методів, недоліком яких $\epsilon$ неможливість точної оцінки попиту на перевезення i неможливість швидкого перебору багатьох варіантів кільцювання схем обігу составів, що $\epsilon$ досить неефективним i впливає на економічну ефективність курсування пасажирських поїздів [2, 3].

Постановка задачі. Для підвищення ефективності системи управління пасажирськими составами на мережі необхідним $\epsilon$ проведення теоретичного обгрунтування процесу розробки плану формування пасажирських поїздів 3 урахуванням схем кільцювання їх составів для можливості пристосування до коливань попиту на перевезення.

Вирішення задачі. Постановка задачі кільцювання схем обігу пасажирських составів має такий вигляд: існують пункти приписки пасажирських составів, що виступають станціями їх формування. В кожному пункті формування ЛВЧД, ВЧ визначена максимальна кількість составів 3 обмеженою місткістю, які можуть бути використані для перевезення пасажирів. На мережі залізниць встановлені можливі пункти оберту составів, причому між кожним пунктом відомі прогнозна кількість пасажирів та експлуатаційні витрати на перевезення одного пасажира 3 урахуванням інфраструктури дільниці. При побудові маршруту прямування пасажирського состава необхідне 
дотримання умови, що маршрут повинен бути замкнений, тобто кожен состав повинен повернутись до пункту приписки, 3 якого почав свій рух. В кожному з пунктів оберту состав повинен побувати лише один раз, тобто необхідно скласти схему кільцювання состава, при цьому не відвідавши пункт оберту двічі. Критерієм формування схем кільцювання на мережі $є$ мінімізація сумарних транспортних витрат кожного состава на мережі. На рис. 1 наведено схематичне подання вхідних та вихідних даних для розв'язання задачі кільцювання пасажирських составів.

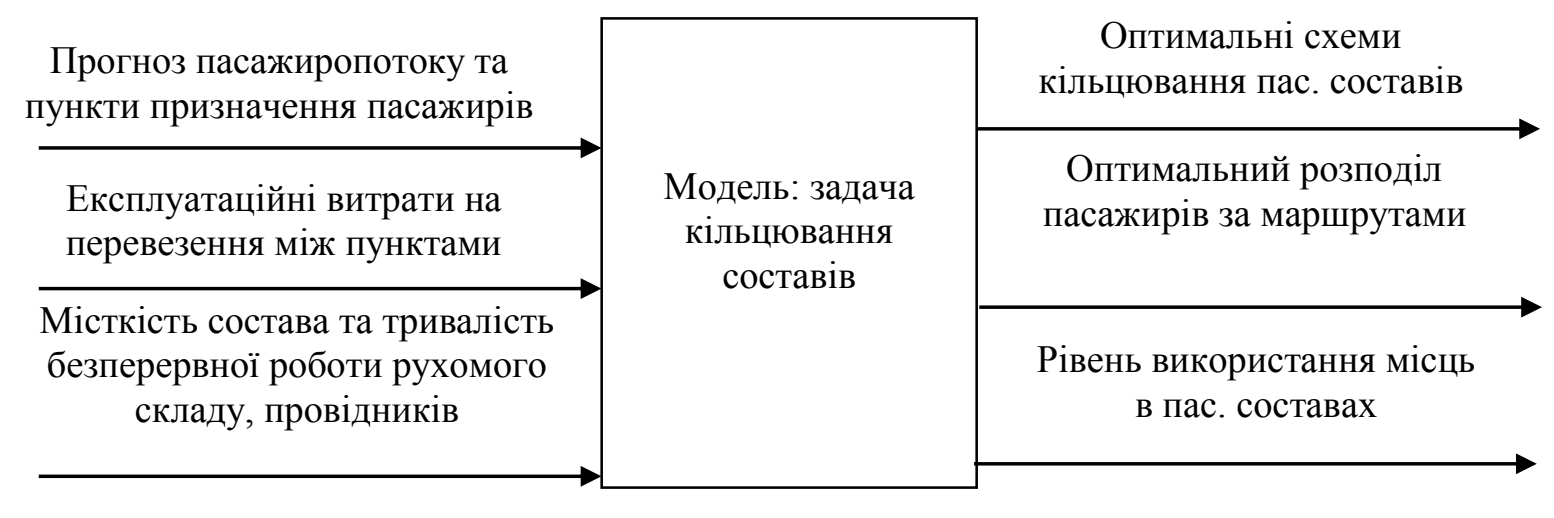

Вхідні дані моделі

Рис. 1. Вхідні та вихідні дані задачі вибору схем кільцювання пасажирських составів

Задачу вибору схем кільцювання пасажирських составів на концептуальному рівні можна описати наступним чином. Задано залізничну мережу у вигляді орієнтованого графу $G(E, A) \quad[4]$, де вершини $E$ графу мережі відповідають станціям формування та оберту пасажирських поїздів, а орієнтовані ребра $A$ фізичного графу відповідають можливим напрямкам призначення пасажирських поїздів. Кожне ребро фізичного графу мережі $G$ подається двома орієнтованими дугами $A_{i, j}, A_{j, i}$ $(A \in[1, n])$ для прямого та зворотного напрямків відповідно (рис. 2). Позначимо через $f_{i j}$ прогнозну величину інтенсивності пасажиропотоку із $i$ в $j$.

Згідно $з$ графом залізничної мережі задана матриця $\mathrm{C}=\left\|\mathrm{c}_{\mathrm{ij}}\right\| \quad$ вартості перевезення одиниці потоку між пунктами $i \operatorname{ma~} j(i=\overline{1, n} ; \quad \boldsymbol{j}=\overline{\mathbf{1} \boldsymbol{n}} \boldsymbol{i} \neq \boldsymbol{j})$ та матриця $\mathrm{F}=\left\|\mathrm{f}_{\mathrm{ij}}\right\|, \quad$ що відповідає інтенсивності пасажиропотоків між пунктами $i m a j$, де $i, j \in E$. Для визначення загального часу руху поїзда за маршрутом кожній дузі $(i, j)$ мережі відповідає час його знаходження в дорозі $t_{i, j}$ між станцією $i$ та станцією $j$.

Вершини $E=p \cup q$ для кожного состава поділяються на вершини $p$, що відповідають пунктам дислокації (приписки составів), та вершини $q$, що відповідають станціям можливого прослідування та оберту пасажирських составів.

Позначимо індексом $k$ пасажирський состав, де $k=\overline{1, v}, k \in V, V$ - множина пасажирських составів, що приписані до пункту $p, \quad$ які передбачається використовувати з відповідною середньою місткістю состава. 


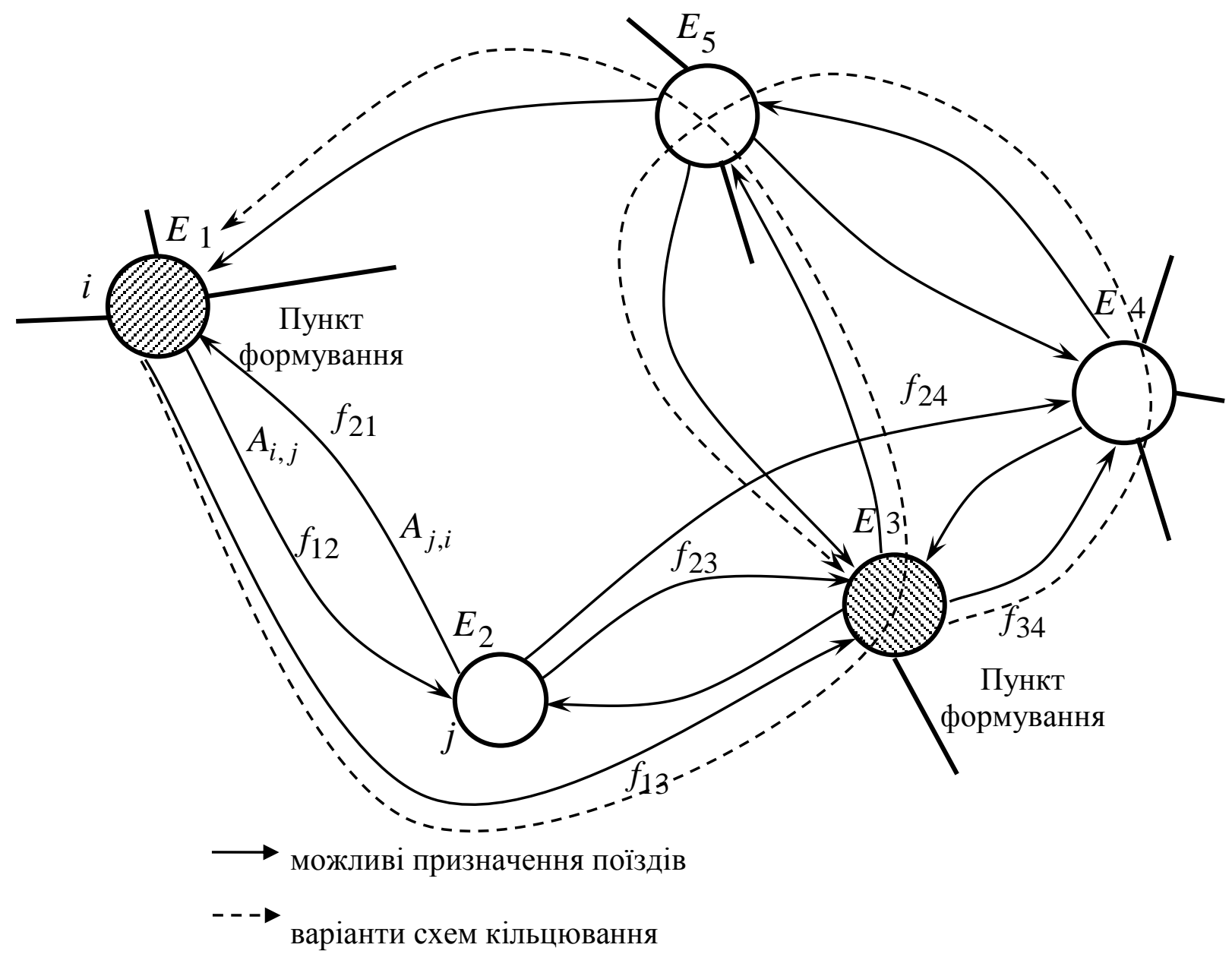

Рис. 2. Граф залізничної мережі $G(E, A)$

Необхідно із множини пунктів оберту для кожного состава визначити схему кільцювання. Очевидно, що в загальному вигляді кільцевим маршрутом обороту состава $є$ послідовність ниток графіка руху, ув'язаних між собою, від початку до кінця маршруту, тобто так званий знайдений гамільтонів цикл на графі $G(E, A)$ (за ім'ям ірландського математика У. Гамільтона) [5].

Для формування варіантів маршруту прямування состава між станціями обороту сформуємо матрицю $X$, елементи якої набувають значення

$$
X_{i j}^{k}=\left\{\begin{array}{llll}
1, & \text { якщо } & \text { маршрут } & \text { прямування існує } \\
0, & \text { в } & \text { іншому } & \text { випадку. }
\end{array}\right.
$$

Оскільки напрямок прямування пасажирського поїзда 3 кожної опорної станції повинен бути визначений однозначно, на змінну $X_{k l}$ накладається обмеження, що однозначно визначає відправлення состава 3 кожного пункту лише один раз 


$$
\sum_{i=1}^{n} X_{i j}^{k}=1, i=\overline{1, n}
$$

Тоді повинна існувати умова, за якою кожен состав $k$ прибуває в кожний пункт оберту тільки один раз,

$$
\sum_{j=1}^{n} X_{i j}^{k}=1, j=\overline{1, n}
$$

Для забезпечення замкнутості маршруту, що містить $n$ пунктів оберту, і не містить замкнутих внутрішніх петель, необхідним $є$ дотримання обмеження

$$
\begin{gathered}
U_{i}-U_{j}+n \cdot X_{i j} \leq n-1, i, j=\overline{1, n}, i \neq j . \\
\text { де } X_{i j} \in\{0,1\}, i=\overline{1, n} ; j=\overline{1, n}
\end{gathered}
$$

Окрім структурних обмежень необхідно визначення технологічних умов на схему кільцювання. На час обігу состава накладається обмеження, при якому сума часу руху состава в прямому та зворотному напрямках до станції приписки состава $j=p \quad$ не повинна перевищувати максимальний час безперервної роботи бригади провідників $l \cdot t_{\sigma p}^{n p o в}$

$$
\sum_{i, j \in E} t_{p, j}^{k}+\sum_{i, j \in E} t_{j, p}^{k} \leq l \cdot t_{\sigma p}^{n p o в}, \forall k \in V
$$

де $l$-ціле число, що визначає дальність маршруту прямування поїзда.

Для задоволення попиту пасажирів на мережі необхідно дотримання обмеження щодо освоєння густоти пасажиропотоків на дільниці

$$
\sum_{k}^{v} \sum_{i=1}^{n} \sum_{j=1}^{n} a^{k} X_{i j}^{k} \geq \varphi \Gamma_{i j}, i=\overline{1, m}
$$

де $a^{k}$ - місткість пасажирського состава $k$;

$\varphi-$ заданий рівень освоєння пасажиропотоку на дільниці;

$\Gamma_{i j}-$ густина пасажиропотоку на дільниці (ij).
Задача вибору схем кільцювання пасажирських составів зводиться до мінімізації витрат на перевезення, де цільова функція має вигляд

$$
F=\sum_{k}^{v} \sum_{i}^{n} \sum_{j}^{n} C_{i j} f_{i j} X_{i j}^{k} \rightarrow \min .
$$

Цільова функція (5) та обмеження (1-5), по суті, дозволяють знайти на графі $G$ відповідно до кількості составів $k$ контури мінімальної довжини, тобто $k$ циклів, що проходять через кожну вершину рівно один раз і мають мінімальну вагу за умови освоєння пасажиропотоку та дотримання обмеження на тривалість безперервної роботи бригад провідників.

Задача зводиться до комбінаторних задач цілочисельного програмування, що відноситься до $N P$-складних [6]. Як відомо 3 математики, для перебору всіх варіантів необхідно провести число перестановок n!, де $\mathrm{n}$ - кількість пунктів. Так як в задачі вибору схем обігу вихідний пункт приймається одним і тим же, то достатньо перебрати всі пункти, що залишилися, тобто кількість перестановок буде дорівнювати (n- 1)! Алгоритм повного перебору майже завжди дає точне рішення задачі, проте тривалість таких обчислень може зайняти недозволено багато часу. Відомо, що при значеннях $\mathrm{n}>12$ сучасний 
комп'ютер не зміг би розв'язати завдання навіть за весь час існування всесвіту. За таких умов необхідним $є$ застосування евристичних методів пошуку наближеного до оптимального розв'язання задачі. Виходячи із умов обчислювальної складності, в роботі для розв'язання поставленої задачі запропоновано використати засіб реалізації процедур евристичного моделювання на базі генетичного алгоритму (англ., Genetic Algorithms [7]).

Реалізація першого етапу роботи алгоритму передбачає подання набору параметрів моделі у формі хромосоми фіксованої довжини 3 урахуванням обмежень на їх діапазони і зведенням їх в один числовий вектор $C_{h}$, що складається 3 двох частин,

$$
\mathrm{C}_{h}=\left(\mathrm{C}^{1} \mathrm{C}^{2}\right)
$$

де $h=\overline{1, K}$ - номер хромосоми C.

Перша частина хромосоми реалізовує гени, що визначають маршрут прямування пасажирського состава між станціями полігону мережі на основі прямого способу подання різних значень індексів пунктів оберту в послідовному порядку, тобто

$$
C^{1}=([2,1, \ldots, i, . ., j, . .5,10, . . n])
$$

відповідно до умови запропонованої технології пошук маршруту прямування поїзда починається 3 другої станції полігону.

Друга частина хромосоми представлена генами, що моделюють пукти зупинки маршруту (після обриву маршруту состав повертається до пункту приписки) для кожного состава. По суті, кількість генів складає $k-1$, i кожне значення гена визначає номер позиції гена в першій частині хромосоми $C^{1}$.

$$
C^{2}=([3,5, \ldots, 10]) .
$$

Наприклад, для 10 пунктів оберту i трьох составів хромосома може мати вигляд $C^{1}=([5,6,9,1,4,2,8,10,3,7])$, тоді як $C^{2}=([3,7])$, що означає перший состав, обертається 3 пункта 5 до 6, потім до 9 та повертається до 5; другий состав 3 пункту 1 до 4, до 2, до 8 і назад до 1; третій состав 3 10 до 3 та 7 і повертається до 10.

Одним із важливих компонентів роботи генетичного алгоритму $\epsilon$ формування фітнес-функції оптимальності для хромосом $\mathrm{C}_{h}=\left(\mathrm{C}^{1} \mathrm{C}^{2}\right)$. Згідно 3 дослідженнями [7], в роботі для обліку обмежень був використаний метод штрафних функцій, що дозволило перетворити задачу умовної оптимізації (1-5) на задачу безумовної оптимізації.

Як спрощений приклад роботи запропонованої моделі еволюційного розвитку, в середовищі Matlab проведено розрахунки щодо визначення схеми обігу пасажирського состава для довільного полігону мережі, що подано на рис. 3. Запропонована процедура еволюційного моделювання дозволила при популяції, рівній 80, та за 5000 генерацій знайти оптимальне рішення за 127,172 секунд (характеристики PC AMD 2,24 Ггц). На рис. 4 наведено графіки залежності значень функцій $F$ від кількості генерацій процедури еволюції.

Висновки. Отриманий результат свідчить, що запропонована процедура генетичного моделювання є ефективним та потужним інструментом розв'язання поставленої задачі. Причому з'являється можливість проведення розрахунків над задачами, розв'язання яких було неможливо класичними методами. Подальшим напрямком досліджень у реалізації технології організації схем обігу пасажирських составів на основі розробленої еволюційної моделі $\epsilon$ створення системи підтримки прийняття рішень оперативного персоналу пасажирських служб залізниць 3 використання WEB-технологій. 


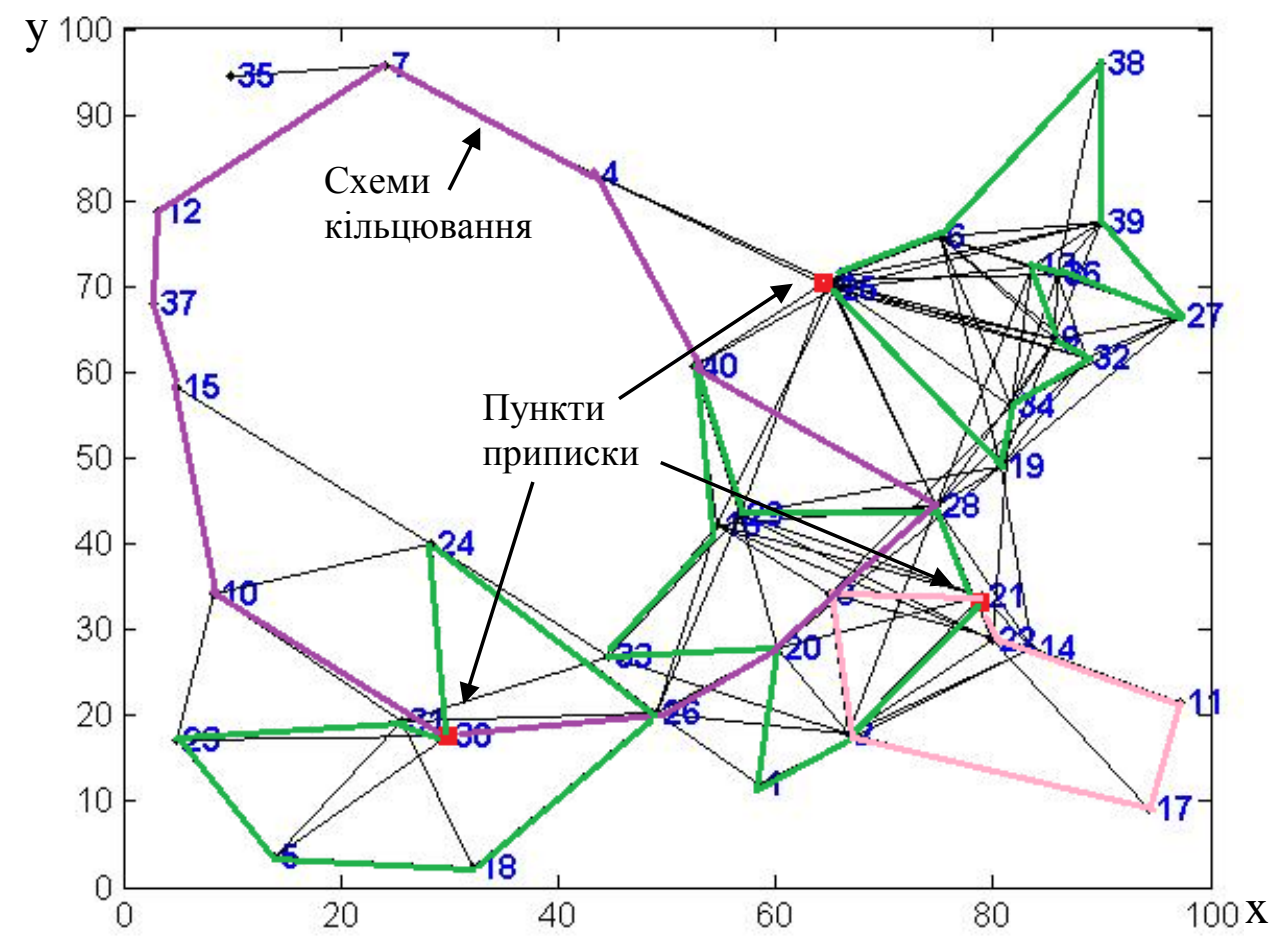

Рис. 3. Схема кільцювання пасажирських составів 3 трьох пунктів приписки на мережі з 39 станцій

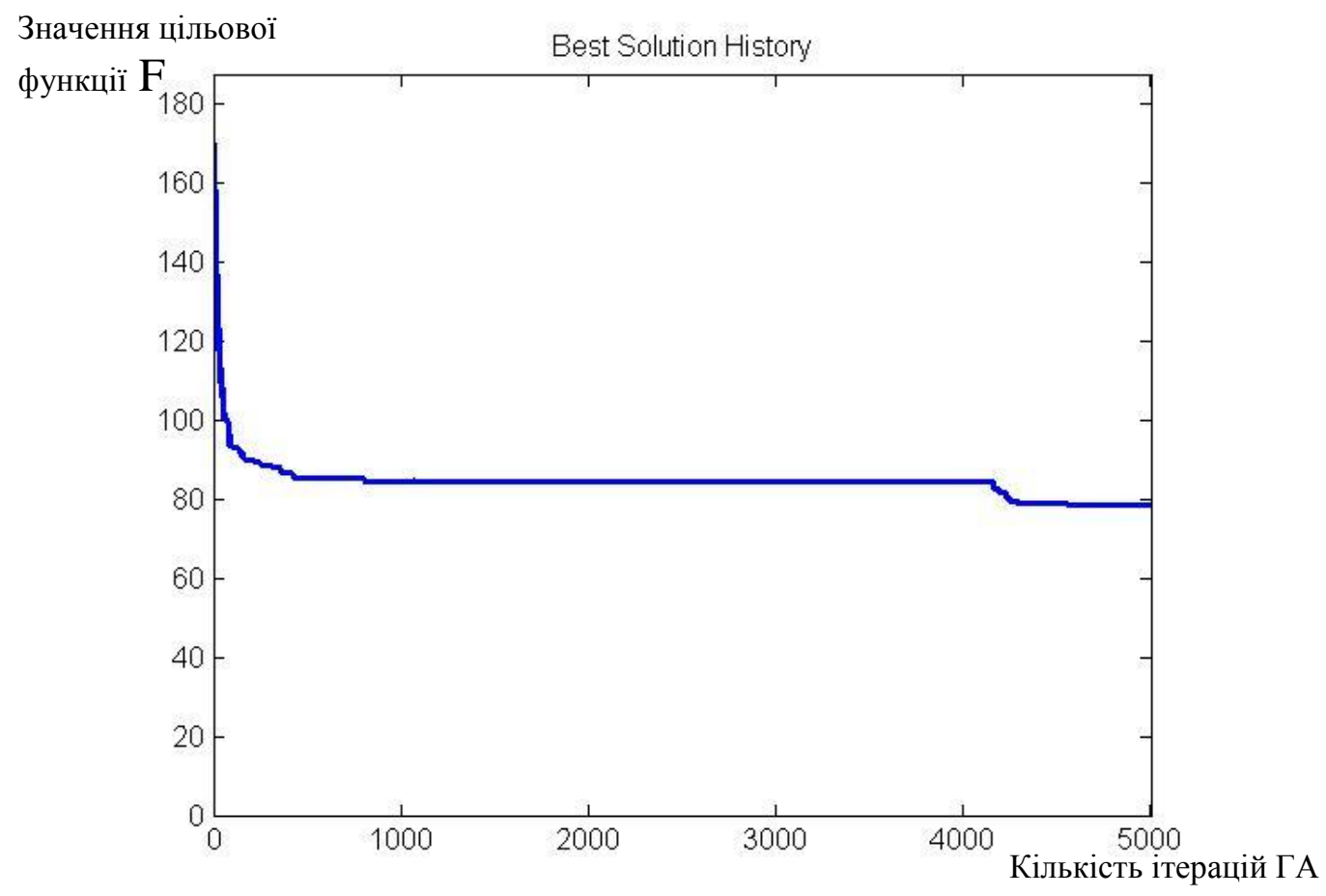

Рис. 4. Графік залежності значень цільової функції $\mathrm{F}$ від кількості генерацій процедури еволюції 
Це дозволить при розв'язанні задач визначення раціональних схем обігу пасажирських составів наблизити ефективність функціонування АСК ПП УЗ до реальних процесів роботи транспорту з урахуванням потреб керівників, що приймають рішення.

\section{Список літератури}

1. Про схвалення Транспортної стратегії України на період до 2020 року [Текст]: Постанова Кабінету Міністрів України від 20.10.2010 р. № 2174-p. - 12 с.

2. Шубко, В.Г. Разработка оптимальной схемы обращения пассажирских поездов на заданном полигоне сети железных дорог [Текст]/ В.Г.Шубко, Ф.С. Гоманков // Тр. МИИТ. 1973. - Вып. 420. - С. 117-129.

3. Прохорченко, А.В. Удосконалення системи прогнозування пасажиропотоків на основі нейро-нечіткого моделювання [Текст] / А.В. Прохорченко, М.В.Кулакова // Зб. наук. праць. - Харків: УкрДАЗТ, 2013. - Вип. 135. - С. 80-84.

4. Харари, Ф. Теория графов [Текст] / Ф. Харари. - М.: Мир, 1973. - 301 с.

5. Azi N. An exact algorithm for a single-vehicle routing problem with time windows and multiple routes / N. Azi, M. Gendreau, J.-Y. Potvin. // European Journal of Operational Research, 20071. - 78. - P. 755-766.

6. Кормен, Т. Алгоритмы: построение и анализ [Текст] / Т. Кормен, Ч. Лейзерсон, Р Ривест. - М.: МЦНМО, 2001. - 120 с.

7. Deb K. Genetic algorithms for function optimization. In: Genetic Algorithms and Soft Computing, Edited by F. Herrera and J. L. Verdegay. Heidelberg: Physica-Verlag, 1996. - P. 3-29.

Ключові слова: план формування пасажирських поїздів, схема обігу состава, математична модель, генетичний алгоритм.

\section{Анотаціï}

Робота присвячена розв'язанню актуальної задачі удосконалення технології кільцювання схем обігу пасажирських составів. Розроблено математичну модель визначення раціональних варіантів ув'язки оберту составів приписки різних залізниць в загальний обіг. Для розв'язання поставленої задачі запропоновано використати засіб реалізації процедур евристичного моделювання на базі генетичного алгоритму.

Работа посвящена решению актуальной задачи совершенствования технологии кольцевания схем обращения пассажирских составов. Разработана математическая модель определения рациональных вариантов увязки оборота составов приписки различных железных дорог в общий оборот. Для решения поставленной задачи предложено использовать средство реализации процедур эвристического моделирования на базе генетического алгоритма.

The work is dedicated to solving the actual problem of improvement of technology banding patterns of circulation of passenger trains. A mathematical model of the definition of rational choices turn trains linking various registry railways in general circulation. To solve this problem suggested to use means of heuristic modeling procedures based on genetic algorithm. 